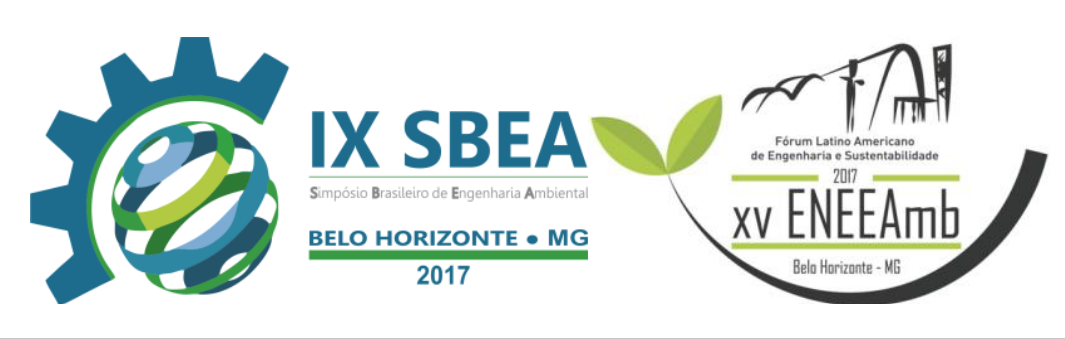

\author{
RESÍDUOS SÓLIDOS
}

\title{
DIAGNÓSTICO DE GESTÃO DE RESÍDUOS SÓLIDOS NO CONDOMÍNIO MORADAS MONTES CLAROS
}

Jusciele Vieira da Silva - juscivieira@live.com

FACET- Faculdades de Ciências Exatas e Tecnológica Santo Agostinho

Cimaria Silva Barbosa - cimariasilva@ yahoo.com.br

FACET- Faculdades de Ciências Exatas e Tecnológica Santo Agostinho

Flávio Lopes da Silva - flaav1@ hotmail.com

FACET- Faculdades de Ciências Exatas e Tecnológica Santo Agostinho

João Lucas Fortes Lopes - lucasforteslopes@yahoo.com.br

FACET- Faculdades de Ciências Exatas e Tecnológica Santo Agostinho

Thayná Aparecida Oliveira Almeida - thay.eco@gmail.com 


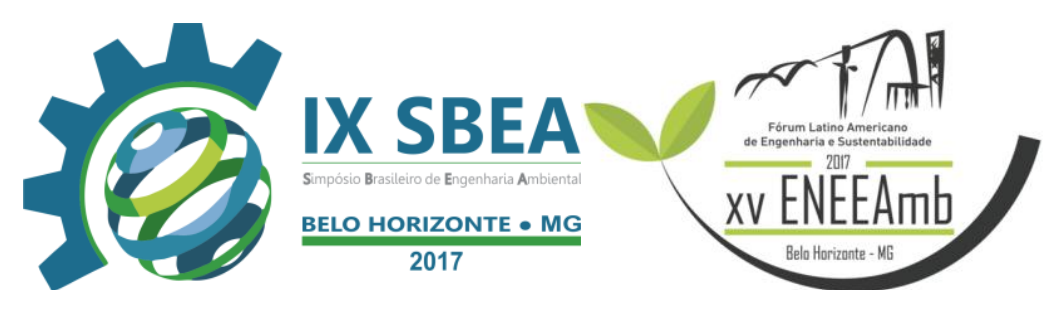

\section{RESUMO}

A Gestão Integrada dos Resíduos Sólidos se constitui em um conjunto de alternativas para reduzir os padrões de produção de consumo atuais, até a sua disposição final adequada e correta, no entanto o presente trabalho vem diagnosticar a gestão de resíduos sólidos no Condomínio Moradas Montes Claros, através de coleta de dados fornecidos pela própria gestão do condomínio, e tem como objetivo, propor medidas compensatórias de vendas desses materiais para melhoria e investimento do condomínio obtendo a redução e reciclagem desses resíduos (papel, metal, vidro e plástico).

Palavras-chave: Condomínio, Gestão, Resíduos Sólidos.

\section{INTRODUÇÃO/OBJETIVO}

Com o constante crescimento da população em diversas áreas do país, aumenta a geração de resíduos que nem sempre são destinados de forma correta. Na atualidade, em consequência do desenvolvimento industrial, crescimento da população e sua adoção crescente de novos padrões de consumo, juntamente com a falta de conhecimento, interesse e sensibilidade da sociedade frente ao meio ambiente, fez ocorrer uma desenfreada produção de "resíduos sólidos urbanos" (DO VALLE et. al).

Com isso, o crescimento está baseado na segurança e proteção ao meio ambiente, desenvolvendo a criação de diversos condomínios particulares e conjuntos habitacionais que visam apenas a elaboração de áreas verdes, mas não realizam um plano de destinação dos resíduos sólidos corretamente. Na cidade de Montes Claros, MG; foi realizado um diagnóstico de geração de resíduos sólidos gerados, para viabilizar a implantação de uma coleta seletiva correta e venda dos materiais recicláveis aproveitáveis para o mercado, este servindo como plano piloto para posteriormente ser implantada em todos os condomínios da cidade.

O modo como os resíduos sólidos são coletados e destinados na maioria das cidades brasileiras e, considerando a heterogeneidade dos resíduos sólidos gerados pela população atual, são necessárias soluções diferenciadas para os resíduos de acordo com as suas características, (SOARES, 2012, P.20). Dependendo da estrutura do condomínio, há necessidade de implantação de educação ambiental capacitando os moradores a fazerem a coleta corretamente, valorizando o material reciclável e evitando o desperdício e geração de resíduos não aproveitáveis.

A Gestão Integrada de Resíduos Sólidos se constitui em um conjunto de alternativas para reduzir os padrões de produção de consumo atuais, até a sua disposição final adequada e correta (OLIVEIRA; SILVA, 2007). O gerenciamento integrado de resíduos sólidos demanda o bem conhecer de alternativas e tecnologias, custos ambientais econômicos, conjuntamente ás alternativas, bem como a forma de sua aplicação em cada região específica (BRAGA; RAMOS, 2006). 


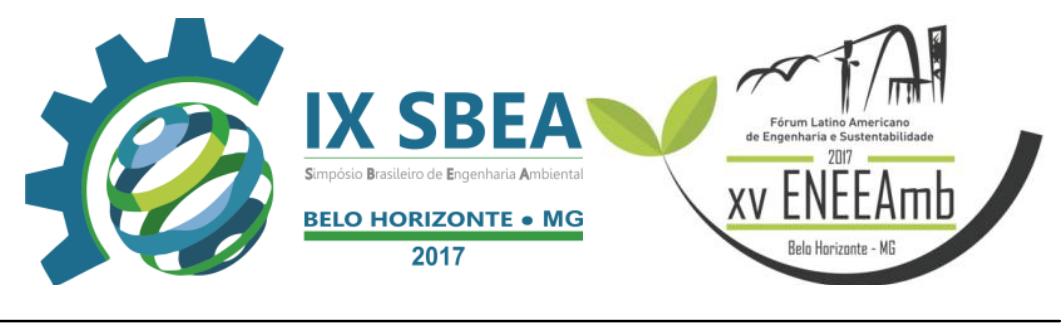

O presente trabalho objetiva-se diagnosticar a geração de resíduos sólidos em um condomínio particular no município de Montes Claros, propondo medidas para redução dos mesmos em sua disposição final.

\section{METODOLOGIA}

\section{1 Área de Estudo}

O estudo realizou-se no Condomínio Moradas Montes Claros, situado no bairro Independência, na cidade de Montes Claros - MG.

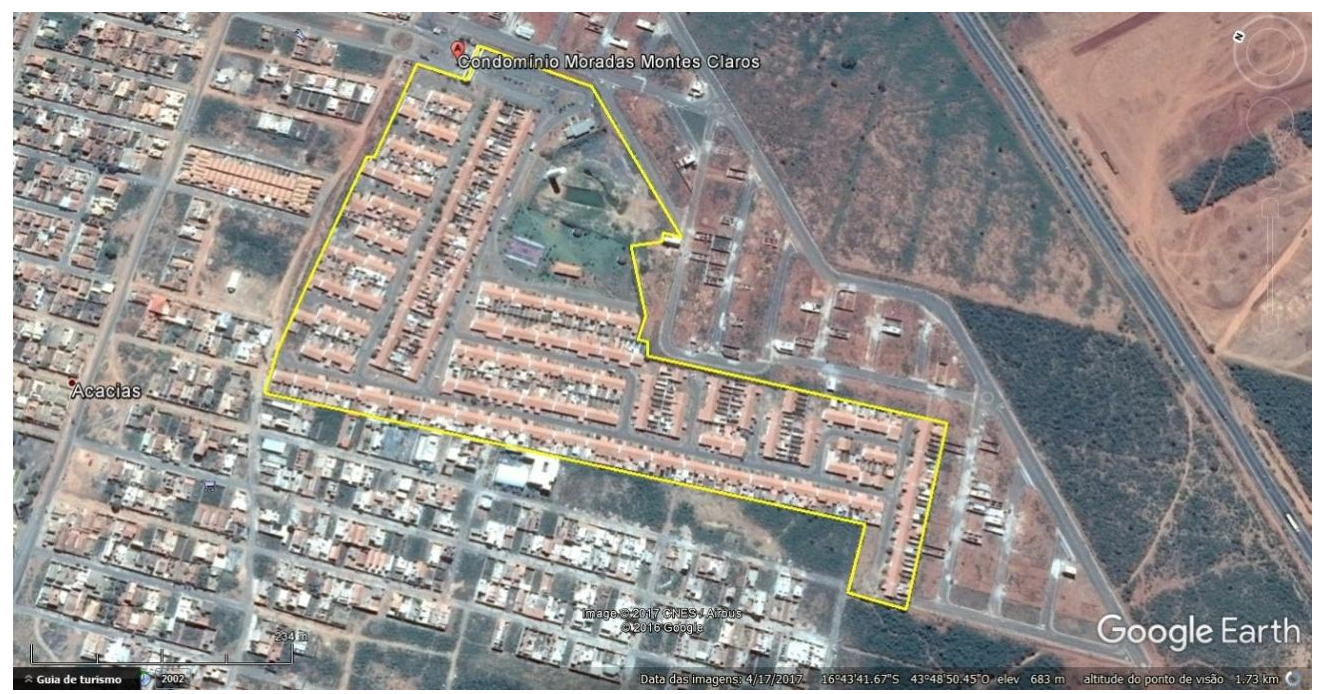

Figura 1: Mapa de Localização.

\subsection{Coleta de Dados}

Os dados foram coletados no Condomínio Moradas Montes Claros no dia 13 de maio de 2017, onde foi feita a visita ao local, registrada através de imagens, e obteve os seguintes dados:

- 598 casa conjugadas

- 1794 habitantes

\section{GERAÇÃO}

O resíduo sólido é gerado através do consumo das residências do condomínio, este representado de forma quantificada pela geração per capta, no caso 0,501842 gramas/habitante.dia.

\section{COLETA}

A coleta do resíduo sólido gerado pelas residências é feito através de um transporte pequeno feito diariamente, usando-se um engate de carroceria em uma motocicleta, é feita a coleta em todas as lixeiras dos condôminos, estocando em um depósito ao lado da portaria, mas do lado de fora do limite do condomínio. 


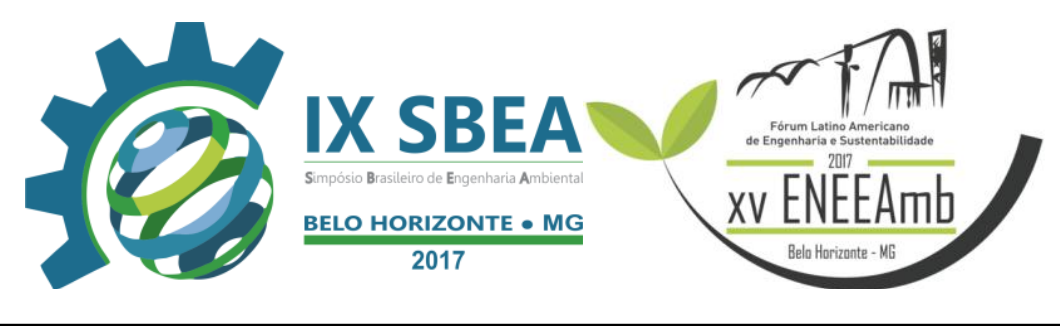

\section{ACONDICIONAMENTO}

Como dito anteriormente, após a coleta, todos os resíduos coletados são devidamente levados para um depósito fora dos limites do condomínio, mas ainda próximo. Este depósito consegue acondicionar até uma semana de geração de resíduos sólidos se haver uma falha na disposição final do mesmo.

\section{SEPARAÇÃO}

Durante a coleta dos resíduos sólidos nas residências, já é feita uma préseparação dos materiais mais valiosos, os quais a gestão do condomínio acondiciona separadamente para ser feito a venda posteriormente. Infelizmente estes materiais separados para serem reciclados são uma pequena parte, visto que é feita a separação apenas de garrafas Pet (de refrigerante) e papelão de caixas amareladas, as mais comuns.

\section{DISPOSIÇÃO FINAL}

A coleta é feita pelo caminhão compactador da prefeitura, ao qual dispõe a realizar a coleta dos resíduos dos condôminos em 03 dias da semana, segunda, quarta e sexta, estes raramente sendo coletados aos finais de semana. Após isso o caminhão compactador leva os resíduos para o aterro sanitário da ViaSOLO, este que detém uma parceria com a Prefeitura Municipal de Montes Claros para depositar seus resíduos, pagando uma taxa por tonelada depositada.
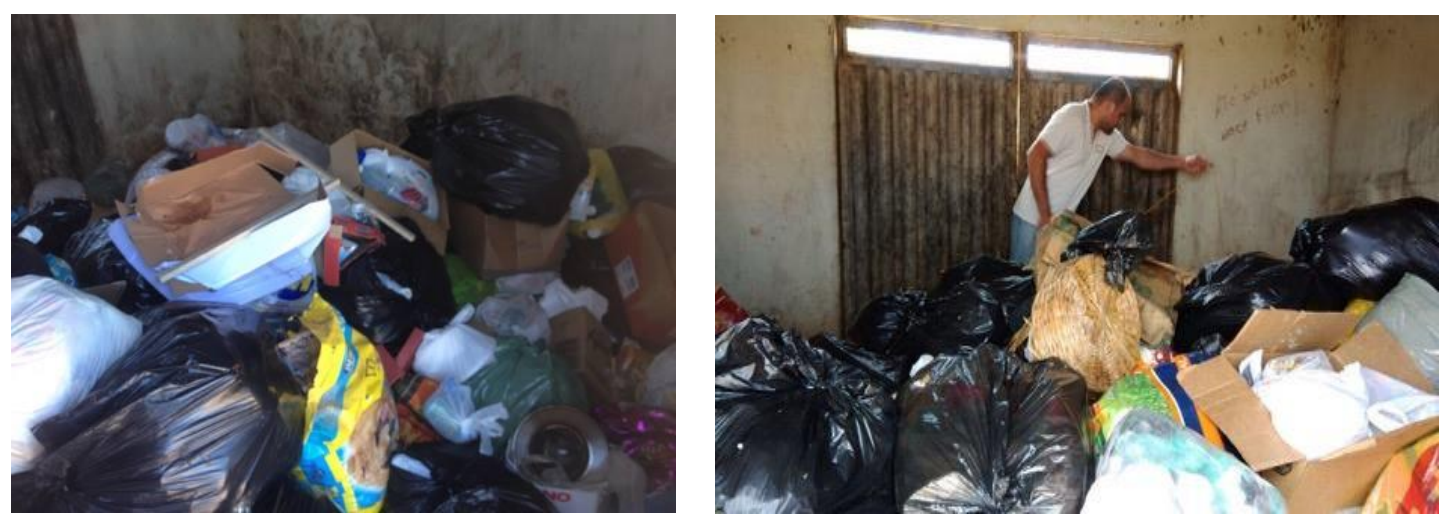

Figura 2 e 3: Galpão de depósito de resíduos sólidos do Condomínio Moradas Montes Claros. Fonte: Próprio autor. Maio, 2017. 


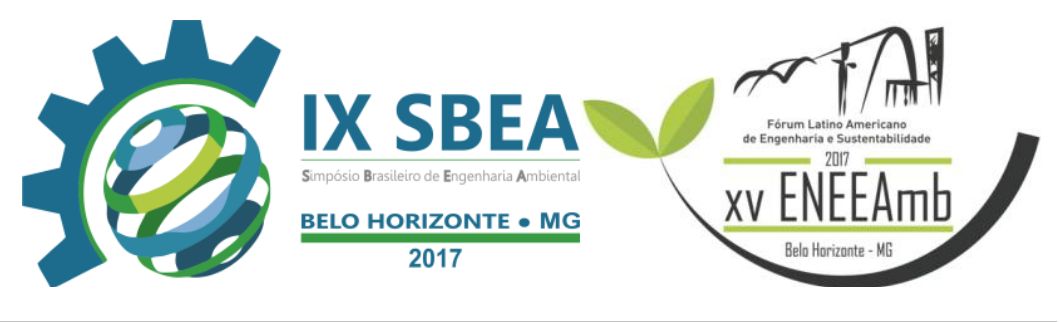

\subsection{Análise de Dados}

Os dados fornecidos pela gestão do condomínio foram calculados a partir da coleta de material em campo que estão descritos a seguir:

O volume arrecadado referente a 2 dias, foi realizado com base das dimensões medidas em campo, em relação à altura, comprimento e largura.

- Volume: $13,6032 \mathrm{~m}^{3}$

Para obter-se a densidade dos resíduos sólidos, foi utilizado um recipiente de 30 litros para coleta e pesagem. E para cálculo da mesma, aplicou-se a seguinte formula:

$$
\mathrm{Y}=\frac{\mathrm{m}}{\mathrm{V}}
$$

Onde:

$\mathrm{Y}=$ densidade $\left(\mathrm{g} / \mathrm{m}^{3}\right)$

$\mathrm{m}=$ massa $($ gramas $)$

$\mathrm{v}=$ volume (metros cúbicos)

Para determinação da composição gravimétrica dos resíduos, realizou-se a separação dos seguintes tipos:

- Orgânico

- Metal

- Papel

- Plástico

- Vidro

- Outros
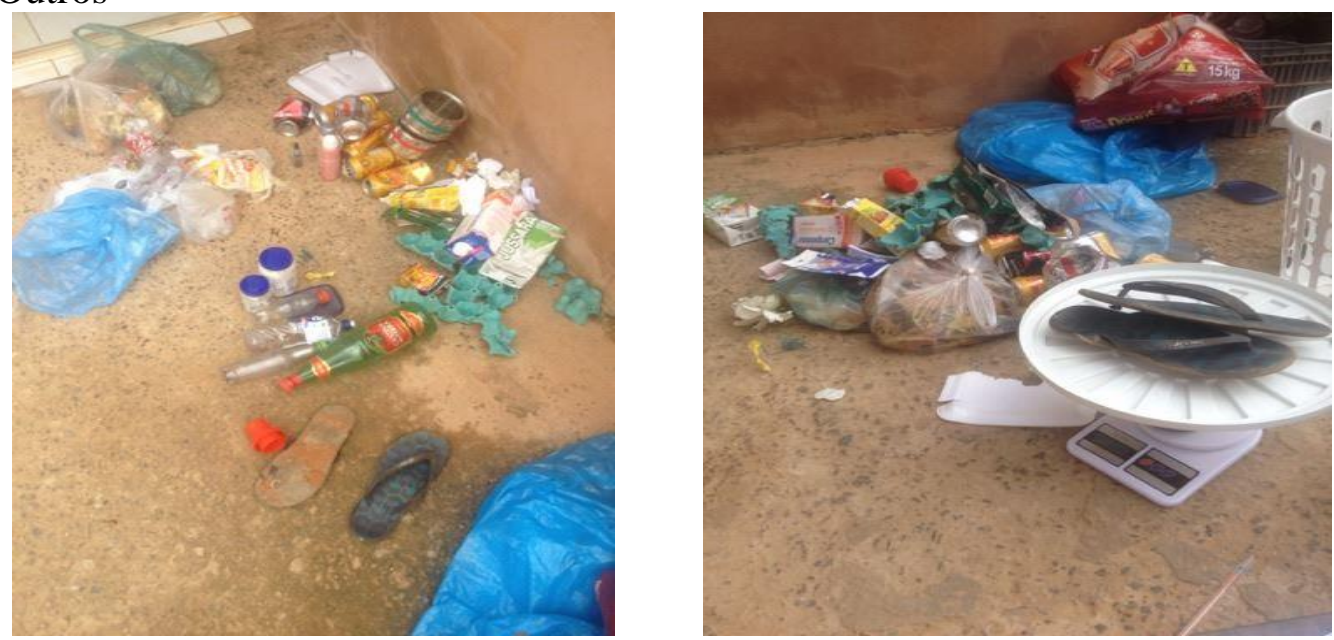

Figura 4 e 5: Separação da amostra dos resíduos coletados e pesagem. Fonte: Próprio autor. Maio, 2017. 


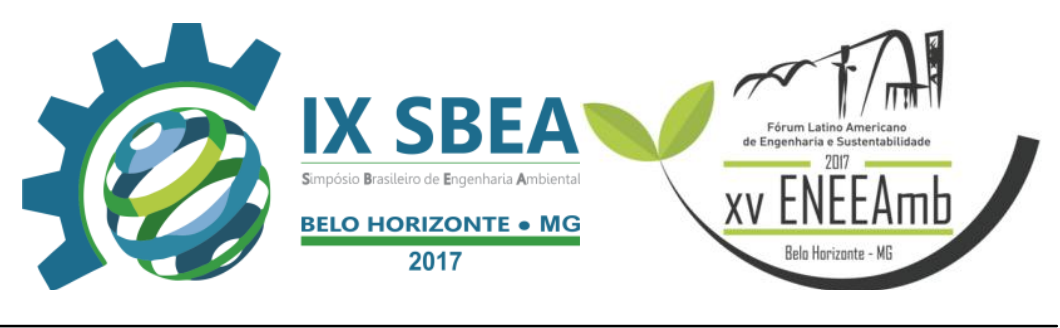

\section{RESULTADOS E DISCUSSÃO}

Segundo os valores levantados em campo, podemos observar o perfil de composição do lixo do Condomínio Moradas Montes Claros, do qual foi feito a divisão em 6 classes distintas, disponibilizando uma quantidade aparentemente boa para a reciclagem. No entanto, devemos salientar com é feito o fluxograma do lixo dentro do local de campo, desde a geração até a disposição final, ao qual iremos propor medidas para reaproveitar ao máximo o lixo gerado, deixando para ser acondicionado e levado ao aterro municipal apenas os rejeitos, resíduo sólido ao qual não possui utilidade de reaproveitamento.

Após as coletas feitas em campos, obtivemos os seguintes resultados para geração de cálculos futuros:

- Massa diária do resíduo sólido gerado no condomínio: 900,3051kg/dia

- Geração per capta: $0,501842 \mathrm{~kg} /$ habitante.dia

Com esses dados, podemos fazer algumas projeções sobre os resíduos totais gerados e suas respectivas composições, com base na separação feita utilizando a amostra coletada em campo.

O volume coletado em campo foi correspondente a um volume de $0,03 \mathrm{~m}^{3}$ de resíduos sólidos, no qual teve um peso de $3,971 \mathrm{~kg}$ e densidade aproximada de $132,3667 \mathrm{~kg} / \mathrm{m}^{3}$, e ainda com a composição gravimétrica representada pelo seguinte gráfico:

\section{Composição Gravimétrica dos Resíduos Sólidos}

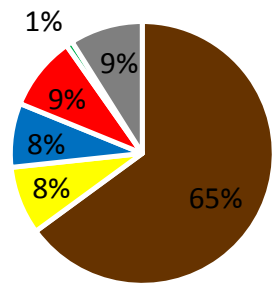

- ORGÂNICO

METAL

- PAPEL

- PLÁSTICO

- VIDROS

Gráfico 2: Composição Gravimétrica da Amostra Coletada em Campo.

Contudo, a maior porcentagem encontrada foi a dos resíduos orgânicos, como esperado por se tratar de um Condomínio residencial. Apesar disso, obtivemos uma grande valia dos os materiais componentes da amostra, tal que surpreendeu o potencial reciclável do mesmo.

A tabela 1 a seguir, mostra a quantificação da geração desses materiais por dia, e uma projeção para cada mês, utilizando a base de 1794 habitantes resultantes no condomínio até o momento e seu perfil consumidor. 

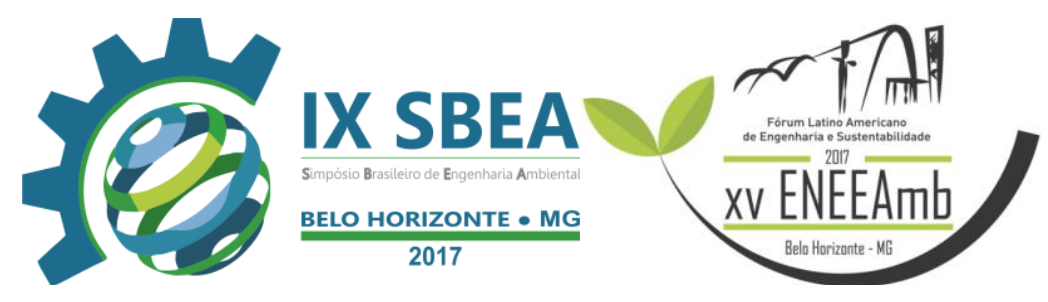

\begin{tabular}{|c|c|c|c|c|}
\hline \multicolumn{3}{|c|}{$\begin{array}{l}\text { COMPOSIÇÃO } \\
\text { GRAVIMÉTRICA }\end{array}$} & $\begin{array}{l}\text { Massa } \\
\text { Diária }\end{array}$ & $\begin{array}{c}\text { Massa } \\
\text { Mensal }\end{array}$ \\
\hline & $\mathrm{g}$ & $\%$ & $\mathrm{~kg}$ & $\mathrm{~kg}$ \\
\hline ORGÂNICO & 2579 & 64,95 & 584,71 & 17541,33 \\
\hline METAL & 332 & 8,36 & 75,27 & 2258,13 \\
\hline PAPEL & 312 & 7,86 & 70,74 & 2122,10 \\
\hline PLÁSTICO & 361 & 9,09 & 81,85 & 2455,38 \\
\hline VIDROS & 32 & 0,81 & 7,26 & 217,65 \\
\hline OUTROS & 355 & 8,94 & 80,49 & 2414,57 \\
\hline TOTAL & 3971 & 100,00 & 900,31 & 27009,15 \\
\hline
\end{tabular}

Tabela 1: Composição Gravimétrica dos materiais e geração por dia/mês.

Após estas análises de resultados feitas, fomentou a preocupação em reciclar esses materiais contidos no "lixo" que estava sendo desperdiçado e sendo depositado em aterro controlado. Com isso, ouve um incremento ao projeto para quantificar a venda dos materiais ali contidos e uma projeção com base econômica do quanto o Condomínio Moradas Montes Claros poderia economizar realizando a coleta correta dos resíduos sólidos e gerando lucro para o mesmo.

Foi levantado que, o condomínio gera em torno de 27 toneladas de resíduos sólidos mensalmente e estes, tendo custo para a Prefeitura Municipal de Montes Claros em torno de $\mathrm{R} \$ 2.160$ reais, este apenas sendo gasto com o transporte $\mathrm{e}$ acondicionamento dos resíduos no aterro controlado que detém parceria com a prefeitura.

Sem levar em conta, este mesmo resíduo poderia obter lucro ao município apenas com a diminuição do volume gerado de rejeitos não recicláveis, e ainda gerar lucro com a venda dos produtos reaproveitados, inclusive do material orgânico (que tem a sua maior representação).

A tabela 2 a seguir, demonstra dados fornecidos por uma empresa de reciclagem de Montes Claros, os quais representam valores que podem ser obtidos com a venda mensal de alguns tipos de materiais para reciclagem. 


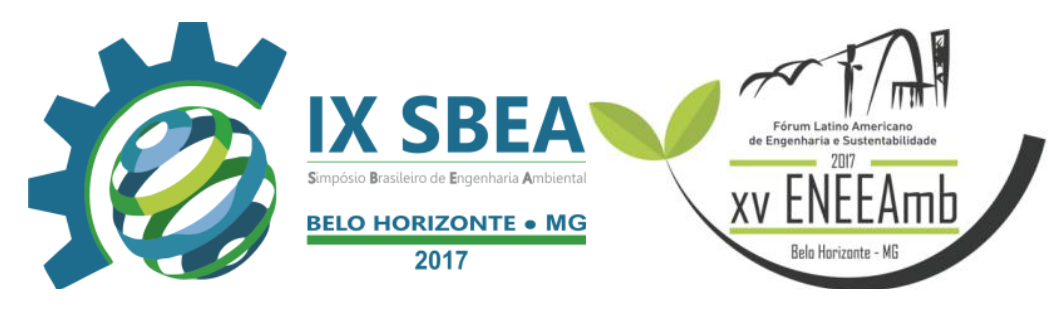

\begin{tabular}{cccc}
\hline & & \multicolumn{2}{c}{$\begin{array}{c}\text { VALOR COM } \\
\text { RECICLÁVEIS }\end{array}$} \\
\hline $\begin{array}{c}\text { RESÍDUOS } \\
\text { SÓLIDOS }\end{array}$ & $\begin{array}{c}\text { Massa } \\
\text { Mensal }\end{array}$ & $\begin{array}{c}\text { Valor } \\
\text { Unitário }\end{array}$ & $\begin{array}{c}\text { Valor } \\
\text { Global }\end{array}$ \\
\hline METAL & $\mathrm{kg}$ & $\mathbf{R} \$$ & $\mathbf{R} \$$ \\
\hline PAPEL & 2258,13 & $\mathrm{R} \$ 6,00$ & $\mathrm{R} \$ 13.548,78$ \\
\hline PLÁSTICO & 2455,38 & $\mathrm{R} \$ 0,40$ & $\mathrm{R} \$ 982,15$ \\
\hline TOTAL & 6835,61 & & $\mathrm{R} \$ 16.016,40$ \\
\hline
\end{tabular}

Tabela 2: Valor com recicláveis dos resíduos sólidos.

Ainda, podemos propor à gestão do Condomínio Moradas Montes Claros a criação de um mercado para troca de material reciclável dos moradores com produtos gerados com a própria reciclagem dos materiais e com outros produtos industrializados, se o mesmo realizar parcerias com comerciantes da região. Para a grande porcentagem de material orgânico presente nos resíduos sólidos gerados, uma horta dentro do condomínio, onde os moradores que contribuírem com materiais recicláveis, receba um ticket com o valor referente à quantidade de material ao qual contribuiu e este ticket sirva como moeda de troca por mercadorias no mercado ou abatendo a taxa de condomínio.

O condomínio entrará com uma educação voltada para a coleta correta dos resíduos sólidos e o acondicionamento correto, com intuito de não perder o valor na hora da venda do material. Os materiais deverão ser acondicionados em um local especifico perto do escritório da gestão e monitorado constantemente, ao fim de cada mês, será acionado a empresa a qual receberá a coleta do mês para realizar a venda e retornar com o valor arrecadado para o condomínio, gerando assim receita com matériaprima que antes era desperdiçada de forma descontrolada.

\section{CONCLUSÕES/RECOMENDAÇÕES}

Contudo, diante dos estudos realizados no Condomínio Moradas Montes Claros, a redução de resíduos sólidos em sua disposição final é possível. De modo que, suceda o máximo de reaproveitamento e reciclagem de todo material, e contando com a participação efetiva de toda população existente, a fim de que essas medidas também contribuam positivamente e beneficiando todas as partes envolvidas. 


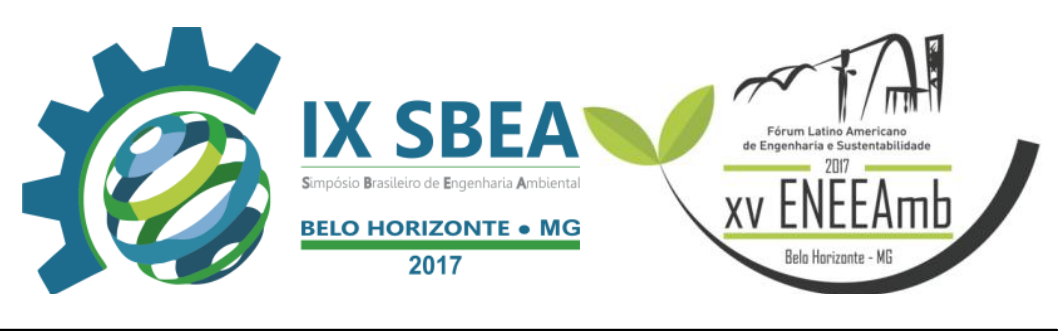

\section{REFERÊNCIAS BIBLIOGRÁFICAS}

DO VALLE, Jair; BRAZ, Eliane Marta Quiñones; DOS SANTOS, Carlos Lopes. RESÍDUOS SÓLIDOS URBANOS.

SOARES, L. M. P. Influência de diferentes doses de compostos produzidos no sistema de tratamento descentralizado de resíduos só- lidos orgânicos domiciliares para o desenvolvimento de tomateiro. (Lycopersicum esculentum). 2012. 63f. Monografia de Licenciatura Plena em Ciências Biológicas da Universidade Estadual da Paraíba. Campina Grande/PB, 2012.

OLIVEIRA, I. S.; SILVA, M. M. P. Educação Ambiental em comunidade eclesial de base na cidade de Campina Grande: contribuição para o processo de mobilização social. Rev. Eletrônica Mestr. Educ. Ambient, v.18, janeiro a julho de 2007.

BRAGA, M. C. B.; RAMOS, S. I. P. Desenvolvimento de um modelo de banco de dados para sistematização de programas de gerenciamento integrado de resíduos sólidos em serviços de limpeza pública. Eng. Sanit. Ambient, v.11, n. 2 , p. $162-168,2006$ 